\title{
Review Article \\ PTH1R-CaSR Cross Talk: New Treatment Options for Breast Cancer Osteolytic Bone Metastases
}

\author{
Yanmei Yang and Bin Wang (i) \\ Center for Translational Medicine, Department of Medicine, Sidney Kimmel Medical College, Thomas Jefferson University, \\ Philadelphia, PA 19107, USA \\ Correspondence should be addressed to Bin Wang; bin.wang@jefferson.edu
}

Received 7 May 2018; Accepted 14 July 2018; Published 29 July 2018

Academic Editor: Kazuhiro Shiizaki

Copyright (c) 2018 Yanmei Yang and Bin Wang. This is an open access article distributed under the Creative Commons Attribution License, which permits unrestricted use, distribution, and reproduction in any medium, provided the original work is properly cited.

\begin{abstract}
Metastatic breast cancer $(\mathrm{BrCa})$ is currently incurable despite great improvements in treatment of primary BrCa. The incidence of skeletal metastases in advanced $\mathrm{BrCa}$ occurs up to $70 \%$. Recent findings have established that the distribution of $\mathrm{BrCa}$ metastases to the skeleton is not a random process but due to the favorable microenvironment for tumor invasion and growth. The complex interplay among $\mathrm{BrCa}$ cells, stromal/osteoblastic cells, and osteoclasts in the osseous microenvironment creates a bone-tumor vicious cycle (a feed-forward loop) that results in excessive bone destruction and progressive tumor growth. Both the type 1 PTH receptor (PTH1R) and extracellular calcium-sensing receptor (CaSR) participate in the vicious cycle and influence the skeletal metastatic niche. Thus, this review focuses on how the PTH1R and CaSR signaling pathways interact and contribute to the pathogenesis of BrCa bone metastases. The effects of intermittent PTH and allosteric modulators of CaSR for the use of bone-anabolic agents and prevention of $\mathrm{BrCa}$ bone metastases constitute a proof of principle for therapeutic consideration. Understanding the interplay between PTH1R and CaSR signaling in the development of BrCa bone metastases could lead to a novel therapeutic approach to control both osteolysis and tumor burden in the bone.
\end{abstract}

\section{Introduction}

Breast cancer $(\mathrm{BrCa})$ is the most common cancer and the second leading cause of cancer-associated death in women [1]. Because of the progress made in early detection and surgical treatment of the primary tumor, mortality in BrCa patients is increasingly linked to the metastatic disease. The incidence of bone metastases in advanced $\mathrm{BrCa}$ occurs up to $70 \%$, and only $20 \%$ of those patients survive five years from the time of diagnosis of bone metastasis [2]. Patients with $\mathrm{BrCa}$ bone metastases have severe bone pain, fractures, hypercalcemia, spinal cord compression, and muscle weakness [3], and these skeletal-related events significantly degrade the quality of life. Bone metastases can be treated locally with radiation therapy or surgical therapy. Systemic treatments include hormonal manipulations, cytotoxic chemotherapy, and/or bonetargeted therapy. However, there is little hope of a cure for
BrCa skeletal metastases. Current management of metastatic bone complications is limited to the use of antiresorptive drugs such as bisphosphonates and receptor activator of nuclear factor- $\kappa \mathrm{B}$ ligand (RANKL) inhibitors, but the osteolytic bone disease often progresses, and over $50 \%$ of patients treated with these drugs will have a recurrence with skeletalrelated events [4]. These drugs only inhibit bone resorption but do not restore bone formation and may cause side effects such as osteonecrosis of the jaw and decrease of renal function [5-7]. It has been established that the concerted actions of the type 1 PTH receptor (PTH1R) and extracellular calcium-sensing receptor (CaSR) maintain systemic extracellular ionized calcium $\left(\mathrm{Ca}^{2+}\right)$ physical homeostasis and lactation, which was acknowledged by a number of excellent reviews [8-10]. In this article, we summarize the progress of interplay between the PTH1R and CaSR signaling in a vicious cycle of $\mathrm{BrCa}$ bone metastases, and interference of 
TABLE 1: Similarity and difference between PTH and PTHrP.

\begin{tabular}{|c|c|c|}
\hline & PTH & PTHrP \\
\hline Production & Parathyroid glands & $\begin{array}{l}\text { All cells especially tumor cells } \\
\text { including breast cancer cells }\end{array}$ \\
\hline Protein size & 84 amino acids & $\begin{array}{c}\text { PTHrP is comprised of } 139,141 \text {, or } \\
173 \text { amino acids }\end{array}$ \\
\hline Action mechanism & Acts as an endocrine factor & $\begin{array}{l}\text { Acts as an endocrine, paracrine, } \\
\text { autocrine, or intracrine factor }\end{array}$ \\
\hline Binding to receptor & Binding to both PTH1R and PTH2R & Only binding to PTH1R \\
\hline Nuclear localization sequence & No & Yes, increase of tumor proliferation \\
\hline Promotion of bone resorption & Yes & Yes \\
\hline $\begin{array}{l}\text { Increase of renal tubular } \\
\text { reabsorption of calcium }\end{array}$ & Yes & Yes \\
\hline 1- $\alpha$-Hydroxylase & $\begin{array}{l}\text { Activates its activity to form } 1,25 \text { dihydroxy-vitamin } \mathrm{D} \text { and then } \\
\text { promotes calcium absorption in the intestine }\end{array}$ & No \\
\hline Hyperparathyroidism & Primary and secondary hyperparathyroidism & No \\
\hline $\begin{array}{l}\text { Humoral hypercalcemia of } \\
\text { malignancy }\end{array}$ & No, except parathyroid carcinoma & Yes \\
\hline
\end{tabular}

these interactions could offer new treatment options of $\mathrm{BrCa}$ bone metastases and their complications.

\section{PTH1R and Its Ligands}

PTH-related protein (PTHrP), also known as PTH-like hormone (PTHLH), was originally identified independently by several groups as a causal factor in the humoral hypercalcemia of malignancy [11-14]. The 13 aminoterminal amino acids are highly homologous to those of PTH, and both bind a common PTH1R. PTH is produced by the parathyroid gland and circulates as an endocrine regulator for the maintenance of calcium homeostasis (Table 1). In contrast to PTH, PTHrP is expressed in almost all normal fetal and adult tissues and acts through paracrine or autocrine mechanisms to regulate development and cell differentiation. In addition, PTHrP has the nuclear localization sequence and also acts via intracrine action to promote $\mathrm{BrCa}$ cell proliferation.

There are some conflicting reports on PTHrP function in primary tumors. While circulating levels of PTHrP positively correlate with the more advanced stages of cancer, some clinical studies indicated a good prognostic value for PTHrP in BrCa with less bone metastasis [15]. However, the PTHrP gene has recently been identified in a genomic locus associated with BrCa susceptibility [16]. Furthermore, $\mathrm{Li}$ and colleagues examined the role of PTHrP expression in animal models of $\mathrm{BrCa}$ and found PTHrP drove breast tumor initiation, progression, and metastasis in mice [17]. Taken together, PTHrP contributes to the pathogenesis of BrCa osteolytic bone metastases.

There are two types of the PTH receptor, PTH1R and PTH2R. The PTH1R and PTH2R belong to class B of the superfamily of $G$ protein-coupled receptors (GPCRs) (Table 2). While PTH2R is mainly expressed in the central nervous system, PTH1R is present primarily in the kidney and bone [18] and is also located in the cartilage and breast.
Like other GPCRs, the PTH1R activates multiple downstream signaling cascades by coupling to 4 major groups of $\mathrm{G}$ proteins, $\mathrm{G} \alpha \mathrm{s}, \mathrm{G} \alpha \mathrm{q}, \mathrm{G} \alpha \mathrm{i}$, and $\mathrm{G}_{12 / 13}$. Interaction with cognate ligands of PTH1R, PTH and PTHrP, or biologically active peptide fragments, such as $\mathrm{PTH}(1-34)$, results in activation of $\mathrm{G} \alpha$ s and $\mathrm{G} \alpha \mathrm{q}$ with consequent stimulation of adenylate cyclase and phospholipase C (PLC) [19, 20]. The action of $\mathrm{PTH}$ is also mediated through phospholipase $\mathrm{D}$ and mitogen-activated protein kinases. A cascade of cellspecific events of PTH mediates PTH1R function to regulate extracellular mineral ion homeostasis and bone remodeling.

\section{CaSR and Its Ligands}

The extracellular calcium-sensing receptor (CaSR) belongs to class C of GPCR that signals in response to $\mathrm{Ca}^{2+}$ and other ligands, such as gadolinium, polypeptides, and certain antibiotics $[21,22]$. CaSR is expressed in the parathyroid glands, kidney, bone, normal breast epithelial cells, and BrCa cells [23]. Importantly, BrCa cells spread to the skeleton and express more CaSR than the cells in the primary tumor do [24]. Activation of the CaSR on BrCa cells contributes not only to BrCa cell proliferation and migration but also to the skeletal bone lesions.

In physiological condition, when the circulating $\mathrm{Ca}^{2+}$ level is low, the activation of CaSR in the chief cells of the parathyroid glands is reduced and PTH secretion is subsequently increased. PTH binds to the PTH1R and initiates a cascade of events that enhances renal tubular reabsorption of calcium, increases renal synthesis of $1,25(\mathrm{OH})_{2} \mathrm{D}_{3}$ so as to promote $\mathrm{Ca}^{2+}$ absorption in the intestine, and facilitates osteoclastic bone resorption, thereby maintaining $\mathrm{Ca}^{2+}$ homeostasis [9].

In normal mammary epithelial cells, activation of the CaSR during lactation inhibits PTHrP synthesis and secretion, thereby regulating maternal calcium and bone metabolism. In contrast, in $\mathrm{BrCa}$ cells, the $\mathrm{Ca}^{2+}$ released from 
TABLE 2: Comparison of PTH1R and CaSR.

\begin{tabular}{|c|c|c|}
\hline & PTH1R & CaSR \\
\hline GPCR & Class B family & Class C family \\
\hline Receptor size & Human PTH1R has 593 amino acids & Human CaSR has 1078 amino acids \\
\hline Expression & $\begin{array}{l}\text { Mostly in osteoblast and kidney, also in cartilage, } \\
\text { normal breast epithelial cells, and some breast } \\
\text { cancer cell lines }\end{array}$ & $\begin{array}{l}\text { Parathyroid glands, kidney, bone, normal breast epithelial } \\
\text { cells, and BrCa cells }\end{array}$ \\
\hline G protein & $\mathrm{G} \alpha \mathrm{s}, \mathrm{G} \alpha \mathrm{q}, \mathrm{G} \alpha \mathrm{i}$, and $\mathrm{G}_{12 / 13}$ & $\mathrm{G} \alpha \mathrm{i}, \mathrm{G} \alpha \mathrm{q}, \mathrm{G} \alpha \mathrm{s}$, and $\mathrm{G}_{12 / 13}$ \\
\hline Agonist & PTH and PTHrP & $\begin{array}{l}\text { Type I: inorganic or organic polycations }\left(\mathrm{Ca}^{2+} \text { and } \mathrm{Gd}^{3+}\right) \text {, } \\
\text { polyamines (spermine and spermidine), and } \\
\text { aminoglycoside antibiotics (neomycin) } \\
\text { Type II: positive allosteric modulators } \\
\text { (calcimimetics) - cinacalcet, NPS R-467, NPS R-568, and } \\
\text { AMG } 416\end{array}$ \\
\hline Antagonist & $\operatorname{PTH}(7-34)$ & Negative allosteric modulators (calcilytics): NPS 2143 \\
\hline $\begin{array}{l}\text { Application in treating } \\
\text { BrCa bone metastases }\end{array}$ & $\begin{array}{l}\text { Intermittent } \mathrm{PTH}(1-34) \text { prevents } \mathrm{BrCa} \text { bone } \\
\text { metastases in mouse models }\end{array}$ & $\begin{array}{l}\text { Cinacalcet is able to treat severe hypercalcemia caused by } \\
\qquad \mathrm{BrCa} \text { bone metastases }\end{array}$ \\
\hline
\end{tabular}

bony matrix destruction binds to CaSR and stimulates PTHrP secretion [25]. This contradictory function is possible due to the ability of the CaSR to bind and activate different $G$ protein subunits to switch from activation of the pertussis toxin-sensitive G $\alpha$ i and suppression of cAMP levels in the normal mammary epithelial cells to activation of $\mathrm{G} \alpha$ s and stimulation of cAMP levels in BrCa cells in a cell type-specific manner [26].

\section{Role of PTH1R and CaSR in the Bone-Tumor Vicious Cycle}

Tumor metastasis to the secondary site is not a random event but is due to the favorable microenvironment [27, 28]. As early as 1889, Stephen Paget developed the "seed and soil" theory to describe the organ-specific metastasis, which indicates the distribution of tumor cells to certain organs largely depends on the specific feature of metastatic tumor cells ("seed") and particular host microenvironment ("soil") [29]. Primary breast tumors express CXCR4 [30], one of the metastasis markers, and secrete PTHrP. Li et al. reported that PTHrP ablation was accompanied by inhibition of CXCR4 expression in primary breast tumors, suggesting PTHrP is involved in the control of CXCR4 expression and consequently plays an important role in metastatic spread [17]. Osseous marrow stromal cells and osteoblasts secrete many chemokines including CXCL12 [31], which attracts CXCR4 positive BrCa cell homing and colonization to the bone. In response to the bone microenvironment, $\mathrm{BrCa}$ cells metastatic to the skeleton produce more PTHrP than the cells in the primary tumor [32]. Bone marrow stromal cells and osteoblasts, but not osteoclasts, express PTH1R. PTHrP binds to PTH1R mostly to induce G $\alpha$ s/cAMP signaling, which begets RANKL secretion (Figure 1). RANKL binds to its receptor RANK on osteoclast precursor cells and induces the differentiation and maturation of osteoclasts. The activated osteoclasts stimulate bone resorption and subsequent bony matrix destruction. Elevated extracellular $\mathrm{Ca}^{2+}$ released from the resorbed bone binds to $\mathrm{CaSR}$ on metastatic $\mathrm{BrCa}$ cells in the bone microenvironment (Figure 1). Unlike normal breast cells, CaSR activation induces G $\alpha$ s/cAMP pathway in BrCa cells and elicits further PTHrP production [26]. Furthermore, growth factors such as transforming growth factor $\beta$ and insulin-like growth factor 1 that are stored during bone formation are released at sites of bone resorption and synergize with the effects of $\mathrm{Ca}^{2+}$ on CaSR to facilitate PTHrP secretion and worsen osteolysis $[33,34]$. Because of its nuclear localization sequence, PTHrP can also act as an intracrine factor to promote tumor proliferation [21] that is independent of PTH1R (Figure 1) and then augment bone turnover, thereby driving the bonetumor vicious cycle. Thus, the PTHrP-PTH1R interaction initiates the vicious cycle, and the subsequent $\mathrm{Ca}^{2+}$-CaSR signaling amplifies the manifestation of bone metastases, which in turn upregulates PTHrP production, thus setting up a feed-forward loop and exacerbating the osteolytic disease. Therefore, the interplay of PTH1R and CaSR acts in concert to evoke excessive bone destruction and progressive tumor growth.

\section{Targeting the PTH1R and CaSR Signaling for Prevention of BrCa Bone Metastases}

Generally, interference with each component or individual downstream signaling of the bone-tumor vicious cycle will have effects on the treatment of BrCa metastatic bone lesions. Bisphosphonates or RANKL inhibitors are antiresorptive drugs representing the current standard supportive treatment for BrCa bone metastatic complications. Due to a rapid action on inhibition of osteoclast activity, calcitonin may be used to lower the serum calcium levels before antiresorptive drugs exhibit their action in hypercalcemia occurring in $\mathrm{BrCa}$ patients. However, these drugs fail to enhance osteoblastic functions, which are impaired in BrCa patients. Increasing evidence has demonstrated that osteoblasts play a pivotal role in the pathogenesis of $\mathrm{BrCa}$ cell homing and colonization to the bone and subsequent metastatic bone lesions [35-37]. The ideal solution for treatment of $\mathrm{BrCa}$ bone metastases 


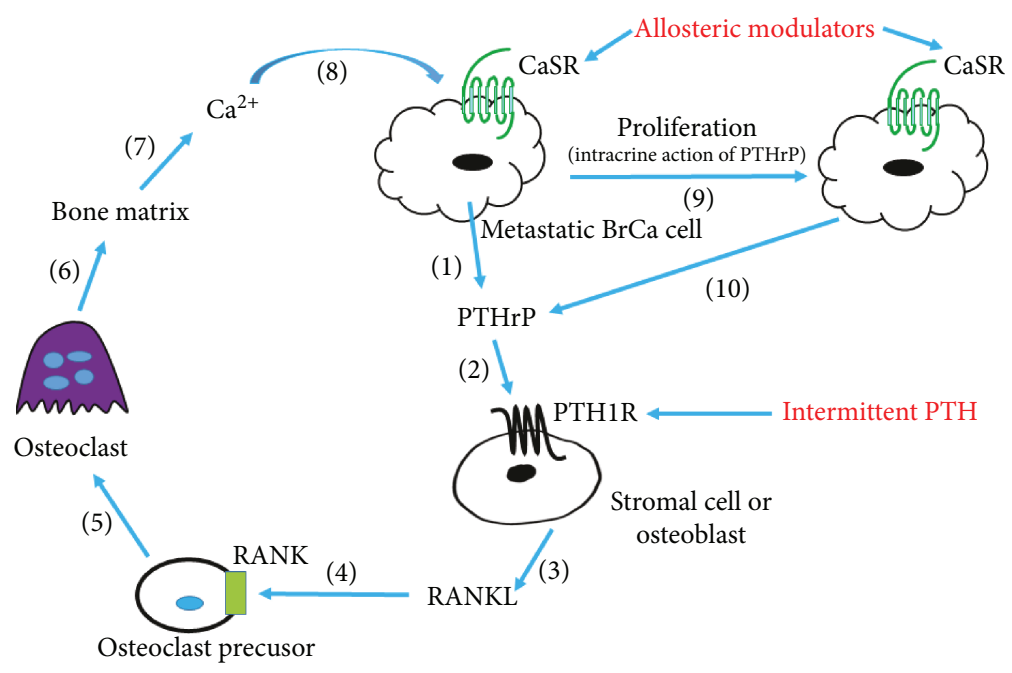

FIGURE 1: Interplay between PTH1R and CaSR plays critical roles in the pathogenesis of BrCa bone metastases. Numbers in parentheses indicate the event sequence during the formation of $\mathrm{BrCa}$ bone metastases. Treatment targets shown in red are likely to inhibit BrCa proliferation, increase osteoblast bone formation, and/or decrease osteoclast bone resorption.

and their associated complications are (1) to block metastatic BrCa cell growth, (2) to generate an unfavorable bone microenvironment for BrCa cell colonization, and (3) to target the upstream signaling in the tumor-bone vicious cycle. Targeting PTHrP-PTH1R and $\mathrm{Ca}^{2+}$-CaSR signaling cascades meets these criteria and will generate new treatment options for prevention of $\mathrm{BrCa}$ metastases to the skeleton.

5.1. Intermittent Recombinant $P T H(1-34)$ or Synthetic $P T H r P(1-34)$ Analog. The bone is a metabolically active organ that undergoes continuous remodeling through the concerted actions of osteoblastic bone formation and osteoclastic bone resorption [38]. The bone remodeling balance is shifted toward bone destruction when metastatic $\mathrm{BrCa}$ cells invade and grow within the bone microenvironment. Both the disease of $\mathrm{BrCa}$ and current cancer treatment cause bone destruction during the BrCa progression [39]. Such bone loss occurs more rapidly to a greater degree than normal agerelated osteoporosis [40]. Gregory et al. reported that the changes in bone formation and bone resorption activities were different at early and late stages during development of the bone lesion following intratibial injection of MDAMB-231 human BrCa cells into the tibiae of athymic nude mice [36]. They found out that the early bone loss in the mouse models is due to a significant reduction in new bone formation by osteoblasts rather than increased levels of bone resorption by osteoclasts, indicating osteoblasts play a critical role in the early pathogenesis of $\mathrm{BrCa}$ bone metastasis. However, the current treatment of bone metastatic destruction is largely dependent on bisphosphonates or RANKL inhibitors, which only impede osteoclastic bone resorption but fail to increase osteoblastic bone formation. Thus, an alternative to antiresorptive drugs is anabolic therapy by targeting osteoblasts to promote bone formation.

Long after Bauer and colleagues discovered the anabolic effect of PTH in 1929 [41], recombinant parathyroid hormone $(\mathrm{PTH})(1-34)$ (teriparatide, hereafter referred to as
PTH) was approved as the first anabolic agent for the treatment of osteoporosis in the United States in 2002 [42]. PTH activates multiple signaling pathways, but not all of them are anabolic. Synthetic PTHrP(1-34) analog (abaloparatide) was approved in 2017 for osteoporosis therapy in an attempt to improve the anabolic effects of PTH1R signaling [43]. Both PTH and PTHrP exert either an anabolic or a catabolic effect depending on their doses and time duration of treatment $[44,45]$. Intermittent administration of lowdose PTH or PTHrP increases bone formation, whereas continuous infusion of a high dose of PTH or PTHrP causes bone resorption and hypercalcemia [44, 46, 47]. While anabolic PTH effects on the bone are mediated through the cAMP/PKA signaling pathway $[48,49]$, PLC/PKC signaling has been shown to be inhibitory to the osteoanabolic actions of PTH [50]. It is also known that Wnt/ $\beta$-catenin signaling [51] and other signaling pathways including phospholipase D [52, 53], ERK1/2 [54], and PI3K/AKT [55, 56] contribute to the anabolic PTH action in the bone.

Multiple myeloma (MM) is a hematologic malignancy of plasma cells, and osteolytic bone disease is the most common complication of MM [57]. Bone cells are directly involved in survival and expansion of myeloma cells in the hematopoietic bone marrow $[58,59]$. Since signaling through the PTH1R in the osteoblast lineage regulates bone marrow hematopoietic niches, Pennisi et al. examined whether treating $\mathrm{MM}$ with an osteoblast-activating agent, intermittent PTH, could simultaneously help control bone disease and myeloma cell growth [60]. They demonstrated that PTH was capable of increasing bone mass in myelomatous bones in vivo and that the increased bone formation was associated with reduced tumor burden. The strategy that stimulation of osteoblast activity inhibits MM growth has received continuing interest for the treatment of solid tumors, such as $\mathrm{BrCa}$ and prostate cancer $[61,62]$. Wu and colleagues demonstrated for the first time that intermittent PTH reduced the incidence of $\mathrm{BrCa}$ bone metastases in multiple mouse 
models. They found out that intermittent PTH decreased skeletal metastases and improved survival in the metastatic BrCa mouse model by injection of murine $4 \mathrm{~T} 1 \mathrm{BrCa}$ cells into the mammary fat pads. They further indicated that PTH administration retained its beneficial effect on tumor metastasis by increasing bone formation, decreasing osteoclast formation, and significantly reducing tumor engraftment and tumor burden of both murine and human $\mathrm{BrCa}$ cells in the mouse intratibial models. Since the CXCR4/CXCL12 axis has been established to play an important role in the homing of cancer cells to the bone $[30,31]$, the effect of PTH inhibition of CXCL12 secretion by MC3T3-E1 cells (preosteoblasts) was confirmed. In addition, the mRNA expression of CXCR4 and PTHrP was markedly reduced in primary tumors dissected from mice treated with PTH. Collectively, these experiments clearly demonstrated that treatment of osteoblasts with intermittent PTH reduced migration of both human and murine $\mathrm{BrCa}$ cells and altered the expression of several genes implicated in metastases, thereby rendering the bone marrow hematopoietic niche less favorable for the homing and colonization of cancer cells.

Patients with osteolytic bone metastases currently are not treated with intermittent PTH because concern has been associated with the use of this drug due to the development of osteosarcoma in preclinical studies [63]. However, the Osteosarcoma Surveillance Study, an over 10-year surveillance study initiated in 2003, is a postmarketing commitment to evaluate a potential relationship between teriparatide and development of osteosarcoma and has not detected a pattern indicative of a causal association between teriparatide treatment and osteosarcoma in humans $[64,65]$. Nonetheless, the antitumor effects of PTH provide proof of principle for the use of bone-anabolic agents against MM or BrCa osteolytic bone disease. These findings warrant further investigation for the safety and efficacy of teriparatide or abaloparatide in $\mathrm{MM}$ or BrCa patients.

5.2. Allosteric Modulators of CaSR. Ligands that activate the CaSR termed as calcimimetics include agonists (type I) and positive allosteric modulators (type II) (Table 2). The action of calcimimetics is to inhibit the secretion of PTH. CaSR antagonists are calcilytics that act as negative allosteric modulators and stimulate the secretion of PTH [66]. Although both positive and negative allosteric modulators of the CaSR are already in development, currently, only the positive allosteric modulators are approved for use in humans. Cinacalcet was the first US FDA-approved allosteric GPCR modulator in 2004 and is used for the reduction of hypercalcemia in patients with parathyroid carcinoma and severe primary hyperparathyroidism, who are unable to undergo parathyroidectomy. The treatment of secondary hyperparathyroidism in patients with end-stage renal disease on maintenance dialysis therapy by cinacalcet was also approved [67]. In 2017, etelcalcetide (AMG 416), a secondgeneration calcimimetic agent, was approved by the US FDA for the treatment of secondary hyperparathyroidism in patients with chronic kidney disease on hemodialysis. It is established that excessive secretion of PTHrP by tumors stimulates osteoclastic bone resorption and promotes renal proximal tubular reabsorption of calcium, leading to hypercalcemia of malignancy $[68,69]$. The applications of cinacalcet occurred subsequently in patients with bone metastases of renal cell carcinoma [70] and $\mathrm{BrCa}$ [71] that cause hypercalcemia. Asonitis and colleagues recently reported that a patient with metastatic $\mathrm{BrCa}$ developed severe hypercalcemia in the disease progression [71]. Medical treatment with bisphosphonate (zeledronate) and RANKL inhibitor (denosumab) failed to lower the elevated serum calcium level. Cinacalcet was then added to the medication and effectively reduced tumor-mediated hypercalcemia and maintained the calcium levels within the normal range in this patient.

The mechanisms of cinacalcet effect for use of treatment of BrCa patients with hypercalcemia are not completely understood. CaSR is expressed not only in the parathyroid glands and kidneys but also in bone cells and metastatic $\mathrm{BrCa}$ cells. Expression of CaSR promotes PTHrP secretion in human BrCa cells [33] and increases osteolytic bone metastases associated with decreased bone formation and increased tumor burden in the mouse intratibial model [72]. In vitro, activation of the CaSR with $\mathrm{Ca}^{2+}$ or positive allosteric modulator increased PTHrP secretion by BrCa cells [26, 33]. Frees et al. reported that CaSR antagonist NPS 2143 was able to reverse $\mathrm{Ca}^{2+}$-induced increase in cell adhesion, migration and proliferation in renal carcinoma cells transfected with the CaSR plasmid [73]. However, the effects of CaSR antagonist on CaSR-mediated BrCa bone metastases and osteolytic bone lesions have not been reported yet. The findings from Colloton and colleagues may help understand the pharmacologic effect of cinacalcet on the decrease of hypercalcemia in patients [74]. The mechanism by which cinacalcet lowered serum calcium was investigated in parathyroidectomized rats by injection of high-dose PTHrP to generate hypercalcemia [74]. Cinacalcet attenuated PTHrP-mediated elevations of ionized calcium in the blood, which were accompanied by increased plasma calcitonin. Cinacalcet was also found to attenuate PTHrP-mediated increase of serum calcium in mice bearing C26-DCT colon tumors [74], which do not express CaSR. These results suggest that the cinacalcetmediated decrease in blood calcium is not the result of a direct effect on tumor cells but rather is the result of increased calcitonin release.

Several calcilytic compounds that are antagonists of CaSR have been evaluated as orally active anabolic therapies for postmenopausal osteoporosis, but clinical development of all of them has been abandoned because they lacked tissue selectivity and clinical efficacy [67]. However, the administration of calcilytics for inhibition of CaSR activation has recently been aroused as promising therapies in other diseases such as chronic obstructive pulmonary disease or allergic asthma $[75,76]$ and could also be used for preventing osteolytic bone metastases.

\section{Conclusion}

BrCa bone metastases are common in advanced malignancy. Despite the developments in both anticancer and bone- 
targeted therapies in recent years, new therapeutic strategies remain to be considered. Both PTH1R and CaSR participate in the bone-tumor vicious cycle and influence the skeletal metastatic niche. Teriparatide and abaloparatide have been successfully applied in osteoporosis. CaSR agonist cinacalcet was effectively used to lower the blood calcium level in $\mathrm{BrCa}$ patients with hypercalcemia. The second-generation CaSR agonist etelcalcetide (AMG 416) was recently approved for the treatment of secondary hyperparathyroidism. ${ }^{223}$ Radium dichloride is a calcimimetic that binds preferentially to a newly formed bone in areas of bone metastases, is the first alpha-emitting radionuclide to be developed for clinical use, and is approved for treatment of castration-resistant prostate cancer and symptomatic bone metastases [77]. Those PTH1R- or CasR-based agents influence PTHrPPTH1R and $\mathrm{Ca}^{2+}$-CaSR signaling pathways in the vicious cycle and could be used for preventing bone metastases and their associated bone destruction although their safety and efficacy need to be further evaluated.

\section{Conflicts of Interest}

The authors declare that there is no conflict of interests regarding the publication of this paper.

\section{References}

[1] R. L. Siegel, K. D. Miller, and A. Jemal, "Cancer statistics, 2015," CA: a Cancer Journal for Clinicians, vol. 65, no. 1, pp. 5-29, 2015.

[2] A. B. Mariotto, R. Etzioni, M. Hurlbert, L. Penberthy, and M. Mayer, "Estimation of the number of women living with metastatic breast cancer in the United States," Cancer Epidemiology, Biomarkers \& Prevention, vol. 26, no. 6, pp. 809-815, 2017.

[3] D. L. Waning, K. S. Mohammad, S. Reiken et al., "Excess TGF$\beta$ mediates muscle weakness associated with bone metastases in mice," Nature Medicine, vol. 21, no. 11, pp. 1262-1271, 2015.

[4] R. E. Coleman, P. Major, A. Lipton et al., "Predictive value of bone resorption and formation markers in cancer patients with bone metastases receiving the bisphosphonate zoledronic acid," Journal of Clinical Oncology, vol. 23, no. 22, pp. 49254935, 2005.

[5] A. Bamias, E. Kastritis, C. Bamia et al., "Osteonecrosis of the jaw in cancer after treatment with bisphosphonates: incidence and risk factors," Journal of Clinical Oncology, vol. 23, no. 34, pp. 8580-8587, 2005.

[6] M. Gnant and P. Clezardin, "Direct and indirect anticancer activity of bisphosphonates: a brief review of published literature," Cancer Treatment Reviews, vol. 38, no. 5, pp. 407-415, 2012.

[7] A. Garg, K. Leitzel, S. Ali, and A. Lipton, "Antiresorptive therapy in the management of cancer treatment-induced bone loss," Current Osteoporosis Reports, vol. 13, no. 2, pp. 73-77, 2015.

[8] D. Goltzman and G. N. Hendy, "The calcium-sensing receptor in bone-mechanistic and therapeutic insights," Nature Reviews. Endocrinology, vol. 11, no. 5, pp. 298307, 2015.
[9] C. Santa Maria, Z. Cheng, A. Li et al., "Interplay between CaSR and PTH1R signaling in skeletal development and osteoanabolism," Seminars in Cell \& Developmental Biology, vol. 49, pp. 11-23, 2016.

[10] J. N. Vanhouten and J. J. Wysolmerski, "The calciumsensing receptor in the breast," Best Practice \& Research. Clinical Endocrinology \& Metabolism, vol. 27, no. 3, pp. 403-414, 2013.

[11] J. M. Moseley, M. Kubota, H. Diefenbach-Jagger et al., "Parathyroid hormone-related protein purified from a human lung cancer cell line," Proceedings of the National Academy of Sciences of the United States of America, vol. 84, no. 14, pp. 5048-5052, 1987.

[12] G. J. Strewler, P. H. Stern, J. W. Jacobs et al., "Parathyroid hormonelike protein from human renal carcinoma cells. Structural and functional homology with parathyroid hormone," The Journal of Clinical Investigation, vol. 80, no. 6, pp. 1803-1807, 1987.

[13] S. M. Orland, A. F. Stewart, V. A. Livolsi, and A. J. Wein, "Detection of the hypercalcemic hormone of malignancy in an adrenal cortical carcinoma," The Journal of Urology, vol. 136, no. 5, pp. 1000-1002, 1986.

[14] L. Suva, G. Winslow, R. Wettenhall et al., "A parathyroid hormone-related protein implicated in malignant hypercalcemia: cloning and expression," Science, vol. 237, no. 4817, pp. 893-896, 1987.

[15] M. A. Henderson, J. A. Danks, J. M. Moseley et al., "Parathyroid hormone-related protein production by breast cancers, improved survival, and reduced bone metastases," Journal of the National Cancer Institute, vol. 93, no. 3, pp. 234-237, 2001.

[16] M. Ghoussaini, O. Fletcher, K. Michailidou et al., "Genomewide association analysis identifies three new breast cancer susceptibility loci," Nature Genetics, vol. 44, no. 3, pp. 312$318,2012$.

[17] J. Li, A. C. Karaplis, D. C. Huang et al., "PTHrP drives breast tumor initiation, progression, and metastasis in mice and is a potential therapy target," The Journal of Clinical Investigation, vol. 121, no. 12, pp. 4655-4669, 2011.

[18] T. J. Gardella and J. P. Vilardaga, "International Union of Basic and Clinical Pharmacology. XCIII. The parathyroid hormone receptors-family B G protein-coupled receptors," Pharmacological Reviews, vol. 67, no. 2, pp. 310 337, 2015.

[19] B. Wang, A. Bisello, Y. Yang, G. G. Romero, and P. A. Friedman, "NHERF1 regulates parathyroid hormone receptor membrane retention without affecting recycling," The Journal of Biological Chemistry, vol. 282, no. 50, pp. 36214-36222, 2007.

[20] B. Wang, Y. Yang, A. B. Abou-Samra, and P. A. Friedman, "NHERF1 regulates parathyroid hormone receptor desensitization: interference with beta-arrestin binding," Molecular Pharmacology, vol. 75, no. 5, pp. 1189-1197, 2009.

[21] W. Kim, F. M. Takyar, K. Swan et al., "Calcium-sensing receptor promotes breast cancer by stimulating intracrine actions of parathyroid hormone-related protein," Cancer Research, vol. 76, no. 18, pp. 5348-5360, 2016.

[22] E. M. Brown, G. Gamba, D. Riccardi et al., "Cloning and characterization of an extracellular $\mathrm{Ca}^{2+}$-sensing receptor from bovine parathyroid," Nature, vol. 366, no. 6455, pp. 575-580, 1993. 
[23] I. Cheng, M. E. Klingensmith, N. Chattopadhyay et al., "Identification and localization of the extracellular calcium-sensing receptor in human breast," The Journal of Clinical Endocrinology and Metabolism, vol. 83, no. 2, pp. 703-707, 1998.

[24] R. Mihai, J. Stevens, C. McKinney, and N. B. N. Ibrahim, "Expression of the calcium receptor in human breast cancer-a potential new marker predicting the risk of bone metastases," European Journal of Surgical Oncology, vol. 32, no. 5, pp. 511-515, 2006.

[25] W. Kim and J. J. Wysolmerski, "Calcium-sensing receptor in breast physiology and cancer," Frontiers in Physiology, vol. 7, 2016.

[26] R. Mamillapalli, J. VanHouten, W. Zawalich, and J. Wysolmerski, "Switching of G-protein usage by the calcium-sensing receptor reverses its effect on parathyroid hormone-related protein secretion in normal versus malignant breast cells," The Journal of Biological Chemistry, vol. 283, no. 36, pp. 24435-24447, 2008.

[27] T. R. Coughlin, R. Romero-Moreno, D. E. Mason et al., "Bone: a fertile soil for cancer metastasis," Current Drug Targets, vol. 18, no. 11, pp. 1281-1295, 2017.

[28] J. M. Chirgwin and T. A. Guise, "Molecular mechanisms of tumor-bone interactions in osteolytic metastases," Critical Reviews in Eukaryotic Gene Expression, vol. 10, no. 2, pp. 159-178, 2000.

[29] S. Paget, "The distribution of secondary growths in cancer of the breast. 1889," Cancer Metastasis Reviews, vol. 8, no. 2, pp. 98-101, 1989.

[30] K. E. Luker and G. D. Luker, "Functions of CXCL12 and CXCR4 in breast cancer," Cancer Letters, vol. 238, no. 1, pp. 30-41, 2006.

[31] K. M. Bussard, D. J. Venzon, and A. M. Mastro, "Osteoblasts are a major source of inflammatory cytokines in the tumor microenvironment of bone metastatic breast cancer," Journal of Cellular Biochemistry, vol. 111, no. 5, pp. 11381148, 2010.

[32] G. J. Powell, J. Southby, J. A. Danks et al., "Localization of parathyroid hormone-related protein in breast cancer metastases: increased incidence in bone compared with other sites," Cancer Research, vol. 51, no. 11, pp. 3059-3061, 1991.

[33] J. L. Sanders, N. Chattopadhyay, O. Kifor, T. Yamaguchi, R. R. Butters, and E. M. Brown, "Extracellular calcium-sensing receptor expression and its potential role in regulating parathyroid hormone-related peptide secretion in human breast cancer cell lines," Endocrinology, vol. 141, no. 12, pp. 43574364, 2000.

[34] T. A. Guise and J. M. Chirgwin, "Transforming growth factorbeta in osteolytic breast cancer bone metastases," Clinical Orthopaedics and Related Research, vol. 415, pp. S32-S38, 2003.

[35] H. K. Brown, P. D. Ottewell, C. A. Evans, and I. Holen, "Location matters: osteoblast and osteoclast distribution is modified by the presence and proximity to breast cancer cells in vivo," Clinical \& Experimental Metastasis, vol. 29, no. 8, pp. 927-938, 2012.

[36] L. S. Gregory, W. Choi, L. Burke, and J. A. Clements, "Breast cancer cells induce osteolytic bone lesions in vivo through a reduction in osteoblast activity in mice," PLoS One, vol. 8, no. 9, article e68103, 2013.

[37] Y. Kimura, A. Matsugaki, A. Sekita, and T. Nakano, “Alteration of osteoblast arrangement via direct attack by cancer cells: new insights into bone metastasis," Scientific Reports, vol. 7, no. 1, article 44824, 2017.

[38] L. J. Raggatt and N. C. Partridge, "Cellular and molecular mechanisms of bone remodeling," The Journal of Biological Chemistry, vol. 285, no. 33, pp. 25103-25108, 2010.

[39] S. D’Oronzo, S. Stucci, M. Tucci, and F. Silvestris, "Cancer treatment-induced bone loss (CTIBL): pathogenesis and clinical implications," Cancer Treatment Reviews, vol. 41, no. 9, pp. 798-808, 2015.

[40] P. Taxel, P. Choksi, and C. Van Poznak, "The management of osteoporosis in breast cancer survivors," Maturitas, vol. 73, no. 4, pp. 275-279, 2012.

[41] W. Bauer, J. C. Aub, and F. Albright, "Studies of calcium and phosphorus metabolism: V. A study of the bone trabeculae as a readily available reserve supply of calcium," The Journal of Experimental Medicine, vol. 49, no. 1, pp. 145-162, 1929.

[42] C. Deal and J. Gideon, "Recombinant human PTH 1-34 (Forteo): an anabolic drug for osteoporosis," Cleveland Clinic Journal of Medicine, vol. 70, no. 7, pp. 585-586, 2003.

[43] E. G. Boyce, Y. Mai, and C. Pham, "Abaloparatide: review of a next-generation parathyroid hormone agonist," The Annals of Pharmacotherapy, vol. 52, no. 5, pp. 462-472, 2018.

[44] M. J. Horwitz, M. B. Tedesco, S. M. Sereika et al., "Continuous PTH and PTHrP infusion causes suppression of bone formation and discordant effects on $1,25(\mathrm{OH})_{2}$ vitamin D," Journal of Bone and Mineral Research, vol. 20, no. 10, pp. 1792-1803, 2005.

[45] L. Qin, L. J. Raggatt, and N. C. Partridge, "Parathyroid hormone: a double-edged sword for bone metabolism," Trends in Endocrinology and Metabolism, vol. 15, no. 2, pp. 60-65, 2004.

[46] K. Poole and J. Reeve, "Parathyroid hormone-a bone anabolic and catabolic agent," Current Opinion in Pharmacology, vol. 5, no. 6, pp. 612-617, 2005.

[47] T. J. Martin, "Parathyroid hormone-related protein, its regulation of cartilage and bone development, and role in treating bone diseases," Physiological Reviews, vol. 96, no. 3, pp. 831871, 2016.

[48] J. P. Vilardaga, G. Romero, P. A. Friedman, and T. J. Gardella, "Molecular basis of parathyroid hormone receptor signaling and trafficking: a family B GPCR paradigm," Cellular and Molecular Life Sciences, vol. 68, no. 1, pp. 1-13, 2011.

[49] E. C. Hsiao, B. M. Boudignon, W. C. Chang et al., "Osteoblast expression of an engineered Gs-coupled receptor dramatically increases bone mass," Proceedings of the National Academy of Sciences of the United States of America, vol. 105, no. 4, pp. 1209-1214, 2008.

[50] N. Ogata, Y. Shinoda, N. Wettschureck et al., "G alpha(q) signal in osteoblasts is inhibitory to the osteoanabolic action of parathyroid hormone," The Journal of Biological Chemistry, vol. 286, no. 15, pp. 13733-13740, 2011.

[51] Y. Yang, H. Lei, Y. W. Qiang, and B. Wang, "Ixazomib enhances parathyroid hormone-induced $\beta$-catenin/T-cell factor signaling by dissociating $\beta$-catenin from the parathyroid hormone receptor," Molecular Biology of the Cell, vol. 28, no. 13, pp. 1792-1803, 2017.

[52] A. T. K. Singh, A. Gilchrist, T. Voyno-Yasenetskaya, J. M. Radeff-Huang, and P. H. Stern, "G $\alpha 12 / \mathrm{G} \alpha 13$ subunits of heterotrimeric $G$ proteins mediate parathyroid hormone activation of phospholipase D in UMR-106 osteoblastic cells," Endocrinology, vol. 146, no. 5, pp. 2171-2175, 2005. 
[53] J. L. Garrido, D. Wheeler, L. L. Vega, P. A. Friedman, and G. Romero, "Role of phospholipase D in parathyroid hormone type 1 receptor signaling and trafficking," Molecular Endocrinology, vol. 23, no. 12, pp. 2048-2059, 2009.

[54] J. T. Swarthout, T. A. Doggett, J. L. Lemker, and N. C. Partridge, "Stimulation of extracellular signal-regulated kinases and proliferation in rat osteoblastic cells by parathyroid hormone is protein kinase C-dependent," The Journal of Biological Chemistry, vol. 276, no. 10, pp. 7586-7592, 2001.

[55] T. Yamamoto, F. Kambe, X. Cao, X. Lu, N. Ishiguro, and H. Seo, "Parathyroid hormone activates phosphoinositide 3kinase-Akt-Bad cascade in osteoblast-like cells," Bone, vol. 40, no. 2, pp. 354-359, 2007.

[56] N. Kawamura, F. Kugimiya, Y. Oshima et al., "Akt1 in osteoblasts and osteoclasts controls bone remodeling," PLoS One, vol. 2, no. 10, article e1058, 2007.

[57] D. Toscani, M. Bolzoni, F. Accardi, F. Aversa, and N. Giuliani, "The osteoblastic niche in the context of multiple myeloma," Annals of the New York Academy of Sciences, vol. 1335, no. 1, pp. 45-62, 2015.

[58] M. R. Reagan, L. Liaw, C. J. Rosen, and I. M. Ghobrial, "Dynamic interplay between bone and multiple myeloma: emerging roles of the osteoblast," Bone, vol. 75, pp. 161-169, 2015.

[59] M. M. McDonald, H. Fairfield, C. Falank, and M. R. Reagan, "Adipose, bone, and myeloma: contributions from the microenvironment," Calcified Tissue International, vol. 100, no. 5, pp. 433-448, 2017.

[60] A. Pennisi, W. Ling, X. Li et al., "Consequences of daily administered parathyroid hormone on myeloma growth, bone disease, and molecular profiling of whole myelomatous bone," PLoS One, vol. 5, no. 12, article e15233, 2010.

[61] S. Swami, J. Johnson, L. A. Bettinson et al., "Prevention of breast cancer skeletal metastases with parathyroid hormone," JCI Insight, vol. 2, no. 17, 2017.

[62] Y. Shiozawa, E. A. Pedersen, A. M. Havens et al., "Human prostate cancer metastases target the hematopoietic stem cell niche to establish footholds in mouse bone marrow," The Journal of Clinical Investigation, vol. 121, no. 4, pp. 1298-1312, 2011.

[63] J. L. Vahle, G. G. Long, G. Sandusky, M. Westmore, Y. L. Ma, and M. Sato, "Bone neoplasms in F344 rats given teriparatide $[\operatorname{rhPTH}(1-34)]$ are dependent on duration of treatment and dose," Toxicologic Pathology, vol. 32, no. 4, pp. 426-438, 2004.

[64] E. B. Andrews, A. W. Gilsenan, K. Midkiff et al., "The US postmarketing surveillance study of adult osteosarcoma and teriparatide: study design and findings from the first 7 years," Journal of Bone and Mineral Research, vol. 27, no. 12, pp. 2429-2437, 2012.

[65] T. Elraiyah, M. R. Gionfriddo, and M. H. Murad, "Acting on black box warnings requires a GRADE evidence table and an implementation guide: the case of teriparatide," Journal of Clinical Epidemiology, vol. 68, no. 6, pp. 698-702, 2015.

[66] E. F. Nemeth and D. Shoback, "Calcimimetic and calcilytic drugs for treating bone and mineral-related disorders," Best Practice \& Research. Clinical Endocrinology \& Metabolism, vol. 27, no. 3, pp. 373-384, 2013.

[67] E. F. Nemeth and W. G. Goodman, "Calcimimetic and calcilytic drugs: feats, flops, and futures," Calcified Tissue International, vol. 98, no. 4, pp. 341-358, 2016.
[68] T. A. Guise, J. J. Yin, S. D. Taylor et al., "Evidence for a causal role of parathyroid hormone-related protein in the pathogenesis of human breast cancer-mediated osteolysis," The Journal of Clinical Investigation, vol. 98, no. 7, pp. 1544-1549, 1996.

[69] R. Kremer, J. Li, A. Camirand, and A. C. Karaplis, "Parathyroid hormone related protein (PTHrP) in tumor progression," Advances in Experimental Medicine and Biology, vol. 720, pp. 145-160, 2011.

[70] H. Sternlicht and I. G. Glezerman, "Hypercalcemia of malignancy and new treatment options," Therapeutics and Clinical Risk Management, vol. 11, pp. 1779-1788, 2015.

[71] N. Asonitis, E. Kassi, M. Kokkinos, I. Giovanopoulos, F. Petychaki, and H. Gogas, "Hypercalcemia of malignancy treated with cinacalcet," Endocrinology, Diabetes \& Metabolism Case Reports, vol. 2017, article EDM-17-0118, 2017.

[72] C. Boudot, L. Hénaut, U. Thiem et al., "Overexpression of a functional calcium-sensing receptor dramatically increases osteolytic potential of MDA-MB-231 cells in a mouse model of bone metastasis through epiregulin-mediated osteoprotegerin downregulation," Oncotarget, vol. 8, no. 34, pp. 5646056472, 2017.

[73] S. Frees, I. Breuksch, T. Haber et al., "Calcium-sensing receptor (CaSR) promotes development of bone metastasis in renal cell carcinoma," Oncotarget, vol. 9, no. 21, pp. 15766-15779, 2018.

[74] M. Colloton, E. Shatzen, B. Wiemann et al., "Cinacalcet attenuates hypercalcemia observed in mice bearing either Rice $\mathrm{H}$ 500 Leydig cell or C26-DCT colon tumors," European Journal of Pharmacology, vol. 712, no. 1-3, pp. 8-15, 2013.

[75] P. L. Yarova, A. L. Stewart, V. Sathish et al., "Calcium-sensing receptor antagonists abrogate airway hyperresponsiveness and inflammation in allergic asthma," Science Translational Medicine, vol. 7, no. 284, article 284ra60, 2015.

[76] R. B. Penn, "Physiology. Calcilytics for asthma relief," Science, vol. 348 , no. 6233, pp. 398-399, 2015.

[77] R. Coleman, "Treatment of metastatic bone disease and the emerging role of radium-223," Seminars in Nuclear Medicine, vol. 46, no. 2, pp. 99-104, 2016. 


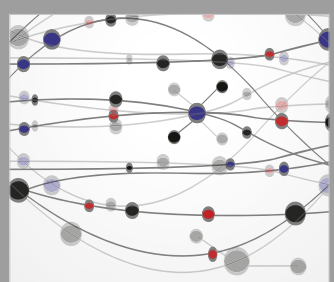

The Scientific World Journal
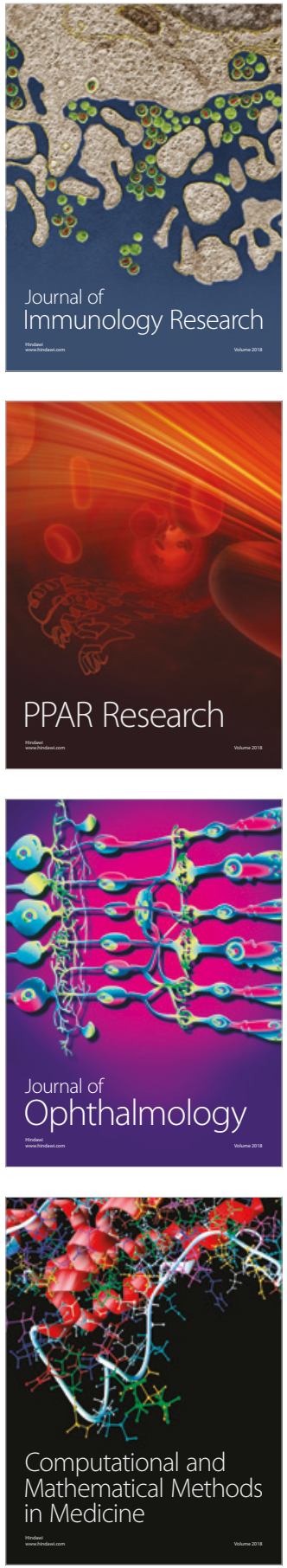

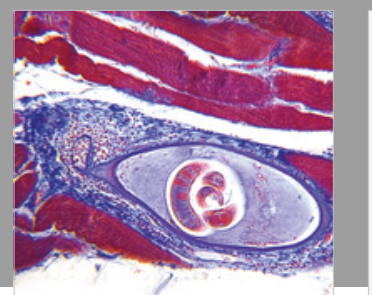

Gastroenterology Research and Practice

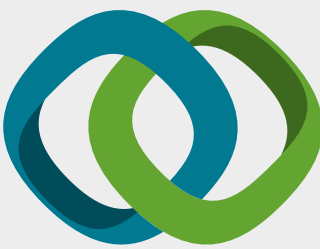

\section{Hindawi}

Submit your manuscripts at

www.hindawi.com
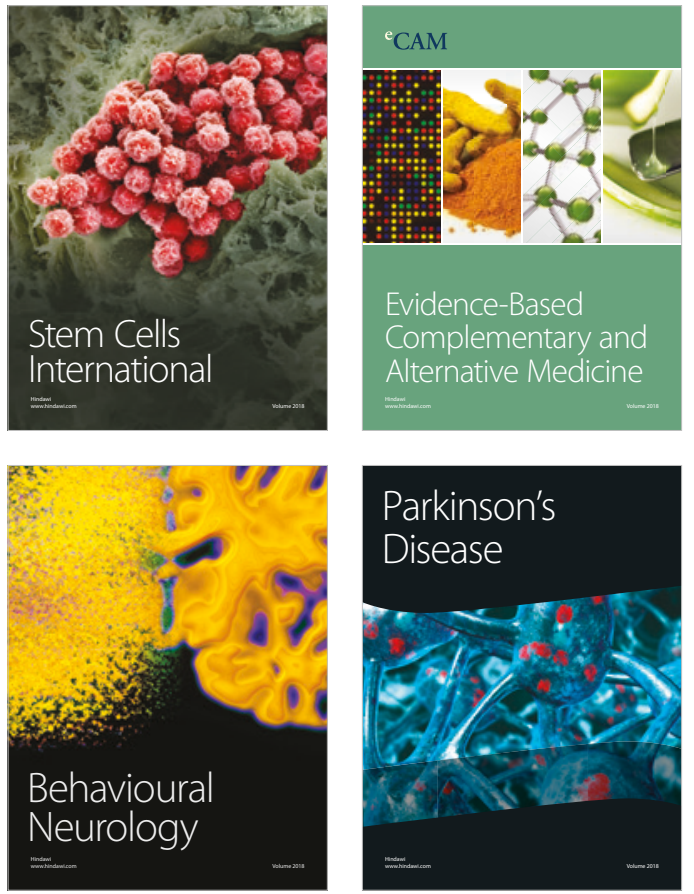

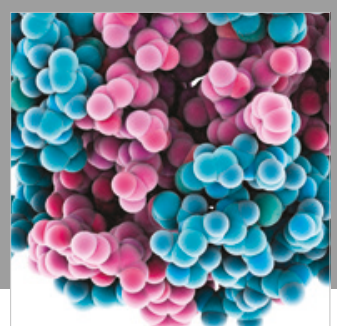

ournal of

Diabetes Research

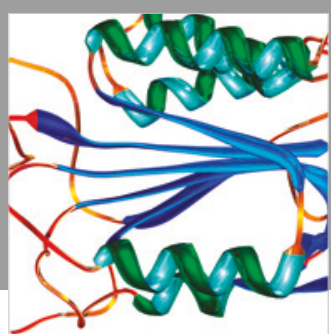

Disease Markers
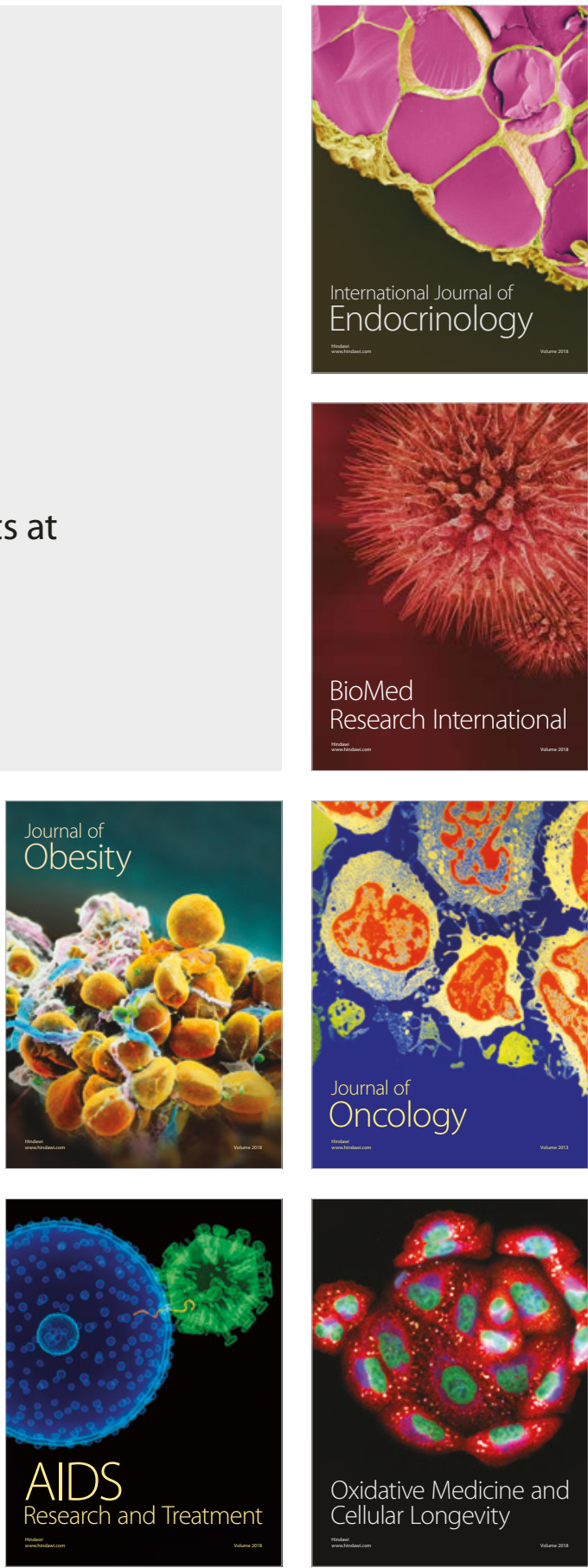